\title{
Involvement of a membrane skeletal protein, 4.1G, for Sertoli/germ cell interaction
}

\author{
Nobuo Terada, Nobuhiko Ohno, Sei Saitoh, Yurika Saitoh, Masayuki Komada ${ }^{1}$, Hiroshi Kubota ${ }^{2}$ \\ and Shinichi Ohno \\ Department of Anatomy and Molecular Histology, Interdisciplinary Graduate School of Medicine and Engineering, \\ University of Yamanashi, 1110 Shimokato, Chuo-City, Yamanashi 409-3898, Japan, ${ }^{1}$ Department of Biological \\ Sciences, Tokyo Institute of Technology, Yokohama, Kanagawa 226-8501, Japan and ${ }^{2}$ Laboratory of Cell and \\ Molecular Biology, Department of Animal Science, School of Veterinary Medicine, Kitasato University, Towada, \\ Aomori 034-8628, Japan \\ Correspondence should be addressed to N Terada; Email: nobuot@yamanashi.ac.jp
}

\begin{abstract}
We previously reported that a membrane skeletal protein, 4.1G (also known as EPB41L2), is immunolocalized in mouse seminiferous tubules. In this study, the 4.1G immunolocalizaiton was precisely evaluated at various stages of the mouse seminiferous epithelial cycle with 'in vivo cryotechnique' and also with pre-embedding immunoelectron microscopy in testicular tissues whose ultrastructures were well preserved with glycerol treatment before cryosectioning. In addition, 4.1G-deficient mice were produced, and the morphology of their seminiferous tubules was also evaluated. The 4.1G immunolocalization was different among stages, indicating that it was not only along cell membranes of Sertoli cells, but also those of spermatogonia and early spermatocytes. To confirm the 4.1G immunolocalization in germ cells, in vitro culture of spermatogonial stem cells (SSCs) was used for immunocytochemistry and immunoblotting analysis. In the cultured SSCs, 4.1G was clearly expressed and immunolocalized along cell membranes, especially at mutual attaching regions. In testicular tissues, cell adhesion molecule-1 (CADM1), an intramembranous adhesion molecule, was colocalized on basal parts of the seminiferous tubules and immunoprecipitated with 4.1G in the tissue lysate. Interestingly, in the 4.1G-deficient mice, histological manifestation of the seminiferous tubules was not different from that in wild-type mice, and the CADM1 was also immunolocalized in the same pattern as that in the wild-type. Moreover, the 4.1G-deficient male mice were fertile. These results were probably due to functional redundancy of unknown membrane skeletal molecules in germ cells. Thus, a novel membrane skeletal protein, 4.1G, was found in germ cells, and considering its interaction with CADM family, it probably has roles in attachment of both Sertoli-germ and germ-germ cells. Reproduction (2010) 139 883-892
\end{abstract}

\section{Introduction}

Protein 4.1G (4.1G; also known as EPB41L2) is a membrane skeletal protein (Parra et al. 1998, Walensky et al. 1998), which is one of 4.1-family proteins originally identified in erythrocytes as $4.1 \mathrm{R}$ containing domains to attach spectrin-actin and intramembranous proteins (glycophorin C and band 3; Discher et al. 1995). In the past decade, some interacting intramembranous proteins of $4.1 \mathrm{G}$ have been documented, such as adenosine receptor (Lu et al. 2004a, 2004b), metabotropic glutamate receptor (Lu et al. 2004a, 2004b, Tateyama \& Kubo 2007), platelet T-cell activating molecule (PTA1, CD226; Ralston et al. 2004), and parathyroid hormone receptor (Saito et al. 2005). Therefore, 4.1-family proteins are thought to have functions to connect various intramembranous proteins including ion channels and receptors to cytoplasmic membrane skeletal proteins as well as signal proteins.
We have reported that $4.1 \mathrm{G}$ is expressed in various cells and tissues including Schwann cells in the peripheral nervous system (Ohno et al. 2007a), microglia in the CNS (Ohno et al. 2005), and also in mouse seminiferous tubules (Terada et al. 2005); however, their functions and actual interacting proteins are still obscure. In the seminiferous tubules, as 4.1G was relatively immunolocalized as round and/or arch-shaped patterns in the basal compartment as well as honeycomb patterns in the adluminal compartment (Terada et al. 2005). In this study, we further evaluated the 4.1G immunolocalization at various stages of the mouse seminiferous cycle with 'in vivo cryotechnique (IVCT)' (Ohno et al. 1996) and found different 4.1G distributions among the various stages. In addition, with immunoelectron microscopy, 4.1G was found to be immunolocalized not only in Sertoli cells, but also in a subset of germ cells including spermatogonium. 
Cell adhesion molecule-1 (CADM1), also designated as SynCAM/TSLC1/SglgSF/RA175/Necl-2, is a $\mathrm{Ca}^{2+}$ independent immunoglobulin-like CADM which homophilically and heterophilically interacts with themselves or with other protein families (Sakisaka et al. 2007). In the seminiferous tubules, CADM1 was reported to function as an intramembranous molecule in germ cells (Wakayama et al. 2001, Wakayama \& Koami 2003). In the testes of CADM1-deficient mice, dysfunction of germ cells has been reported, indicating its indispensable role in spermatogenesis (Surace et al. 2006, van der Weyden et al. 2006, Yamada et al. 2006, Fujita et al. 2007). As the CADM1 has a molecular domain to bind to the 4.1-family proteins (Wakayama \& Iseki 2009), the 4.1G interaction to CADM1 was examined in the present study. Furthermore, to determine whether $4.1 \mathrm{G}$ is indispensable to form mouse seminiferous tubules, we produced genetically 4.1G-deficient mice and examined the morphology of their seminiferous tubules and immunolocalization of CADM1.

\section{Results}

\section{Immunolocalization of $4.1 \mathrm{G}$ in the seminiferous epithelium}

Using IVCT followed by freeze-substitution fixation (FS), structures reflecting native states were well preserved (hematoxylin-eosin (HE) staining in Fig. 1), and 4.1G was immunolocalized as round and/or arch-shaped patterns in the basal compartments and weakly as honeycomb patterns in the adluminal compartment (Fig. 1). These patterns were consistent with our previous report (Terada et al. 2005), as shown with conventional perfusion fixation followed by cryosectioning with sucrose embedding. The present IVCT-FS method also reconfirmed the $4.1 \mathrm{G}$ expression and its similar immunolocalization in mouse seminiferous tubules.

The 4.1G immunolocalizations were different among the various stages of the seminiferous epithelial cycle. At stages I-II of the seminiferous epithelial cycle (Fig. 1a-d), the $4.1 \mathrm{G}$ was markedly immunostained in the basal part of the seminiferous tubule, where early pachytene spermatocytes and type B spermatocytes were present (P, B in Fig. $1 \mathrm{~b}$ and d). Although the intensity of the $4.1 \mathrm{G}$ immunostaining appeared to be weak in the region where early spermatids (S1, S3 in Fig. $1 \mathrm{~b}$ and d) were localized, another region where late spermatocytes (S13, S14 in Fig. 1b and d) were present was relatively strongly immunostained with 4.1G. At stage V (Fig. 1e and f), pachytene spermatocytes were progressively differentiating in lower parts of the adluminal compartment $(P$ in Fig. 1e) where the $4.1 \mathrm{G}$ immunoreactivity was detected $(P$ in Fig. $1 \mathrm{f}$ ) as well as in the region where late spermatids (S15 in Fig. 1f) were present. Interestingly, with differentiation of spermatids from early to late steps,
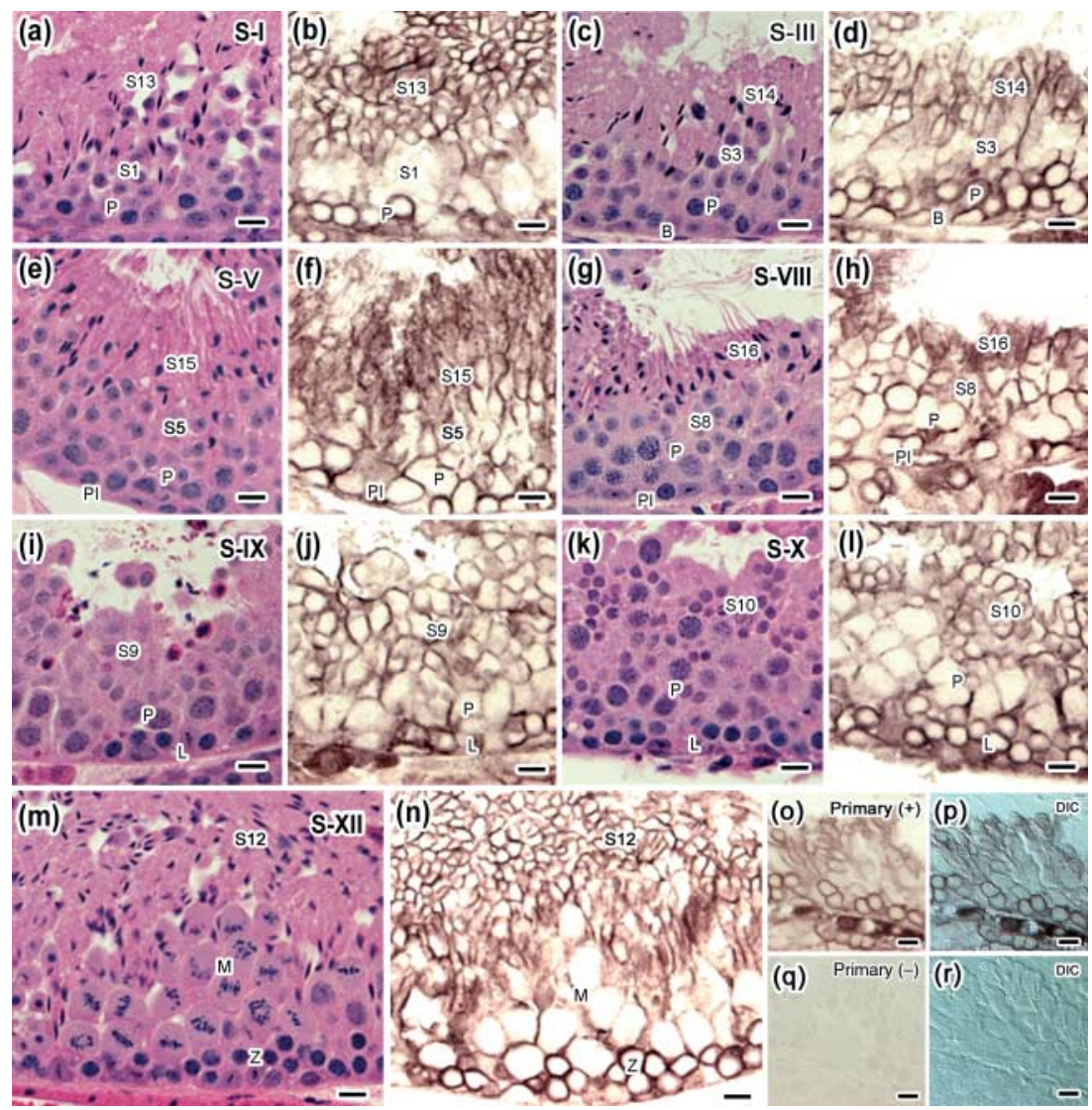

(o)
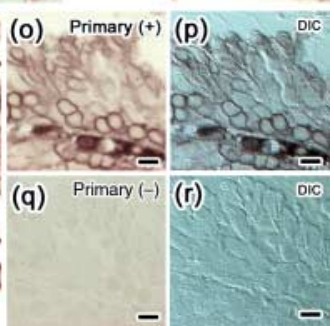

Primary $(+)$

Figure 1 Hematoxylin-eosin staining $(a, c, e, g, i$, $\mathrm{k}$, and $\mathrm{m}$ ) and $4.1 \mathrm{G}$ immunostaining (b, d, f, h, j, l, and $n$ ) in adjacent sections of seminiferous tubules of testicular tissues with in vivo cryotechnique followed by freeze-substitution fixation (IVCT-FS). Images of various stages (S), I (a and b), III (c and d), V (e and f), VIII (g and $h$ ), IX (i and j), X ( $k$ and I), $X I I(m$ and $n$ ), of the mouse seminiferous epithelial cycle are arranged in this panel. Note the line pattern of the $4.1 \mathrm{G}$ immunolocalization at the bottom of seminiferous tubules, including the basal compartment, and also around the top of the adluminal compartment. (o-r) Immunostaining with (o and $p$ ) or without ( $q$ and $r$ ) primary anti4.1G antibody followed with secondary antirabbit $\lg G$ antibody. Both (p) and (r) are diffraction interference contrast (DIC) images corresponding to the immunostaining image of $(\mathrm{o})$ and $(\mathrm{q})$ respectively. $\mathrm{B}$, type $\mathrm{B}$ spermatogonia; $\mathrm{Pl}$, preleptotene spermatocyte; $L$, leptotene spermatocyte; $Z$, zygotene spermatocyte; $P$, pachytene spermatocyte; $M$, meiotic division; $S 1-16$, steps of spermiogenesis. Bars (a-n) $20 \mu \mathrm{m}$. 
the 4.1G immunoreactivity appeared to be stronger (S8, S9 in Fig. $1 \mathrm{~h}$ and j). At stage X (Fig. $1 \mathrm{k}$ and I), 4.1G was immunopositive in leptotene spermatocytes (L in Fig. 1l), whereas its immunostaining intensity was relatively weaker in later pachytene spermatocytes (P in Fig. 1l). At stage XII (Fig. $1 \mathrm{~m}$ and $\mathrm{n}$ ), 4.1G immunostaining was observed in a region where spermatocytes were at zygotene ( $Z$ in Fig. $1 \mathrm{~m}$ and $\mathrm{n}$ ), whereas its intensity appeared to be very weak in the region where spermatocytes differentiated into early spermatids through meiosis ( $M$ in Fig. $1 \mathrm{~m}$ and $\mathrm{n}$ ). In an adjacent section which was immunostained for 4.1G (Fig. 1o and p), the immunostaining was eliminated without the primary anti-4.1G antibody and only with the secondary antibody (Fig. $1 \mathrm{q}$ and $\mathrm{r}$ ). These findings indicate the different expression of $4.1 \mathrm{G}$ at various stages of the seminiferous epithelial cycle.

\section{Immunoelectron microscopy for 4.1G localization}

Because the $4.1 \mathrm{G}$ immunostaining intensity varied at different seminiferous stages in testicular tissues with IVCT as described in the previous paragraph, it seemed that 4.1G was immunolocalized not only in Sertoli cells, but also in germ cells. To more precisely determine the 4.1G immunolocalization in the seminiferous tubules, pre-embedding immunoelectron microscopy was also performed (Fig. 2). To well preserve their ultrastructures, infiltration of $30 \%$ sucrose $/ 10 \%$ glycerol in phosphate buffer (PB) into tissues before freezing and cryosectioning was useful for its cryoprotectant effect. As shown in Fig. 2, because avidin-biotin complex $(A B C)$ and diaminobenzidine $(\mathrm{DAB})$ reaction products were mostly observed under cell membranes, but not in extracellular matrices, it was possible to distinguish between Sertoli and specific staged germ cells.

In addition to the 4.1G immunostaining along cell membranes of Sertoli cells (Se in Fig. 2), other immunoreaction products were also observed in the cytoplasm spermatogonium and some spermatocytes (Sg in Fig. 2). In the spermatogonium, the $4.1 \mathrm{G}$ immunostaining intensity appeared to be strong under the cell membranes facing Sertoli cells (white arrows in Fig. 2c, e-g and j). In some spermatocytes, the 4.1G immunostaining intensity was relatively weak (arrowheads in Fig. $2 \mathrm{~h}$ and i). In the upper half of seminiferous tubules, where spermatocytes and spermatids were mainly localized, the immunoreaction products were not detected along cell membranes of the germ cells, but along those of Sertoli cells (data not shown), as reported before (Terada et al. 2005). These findings indicate that 4.1G was immunolocalized in both Sertoli cells and germ cells at the basal compartment and bottom parts of the adluminal compartment.
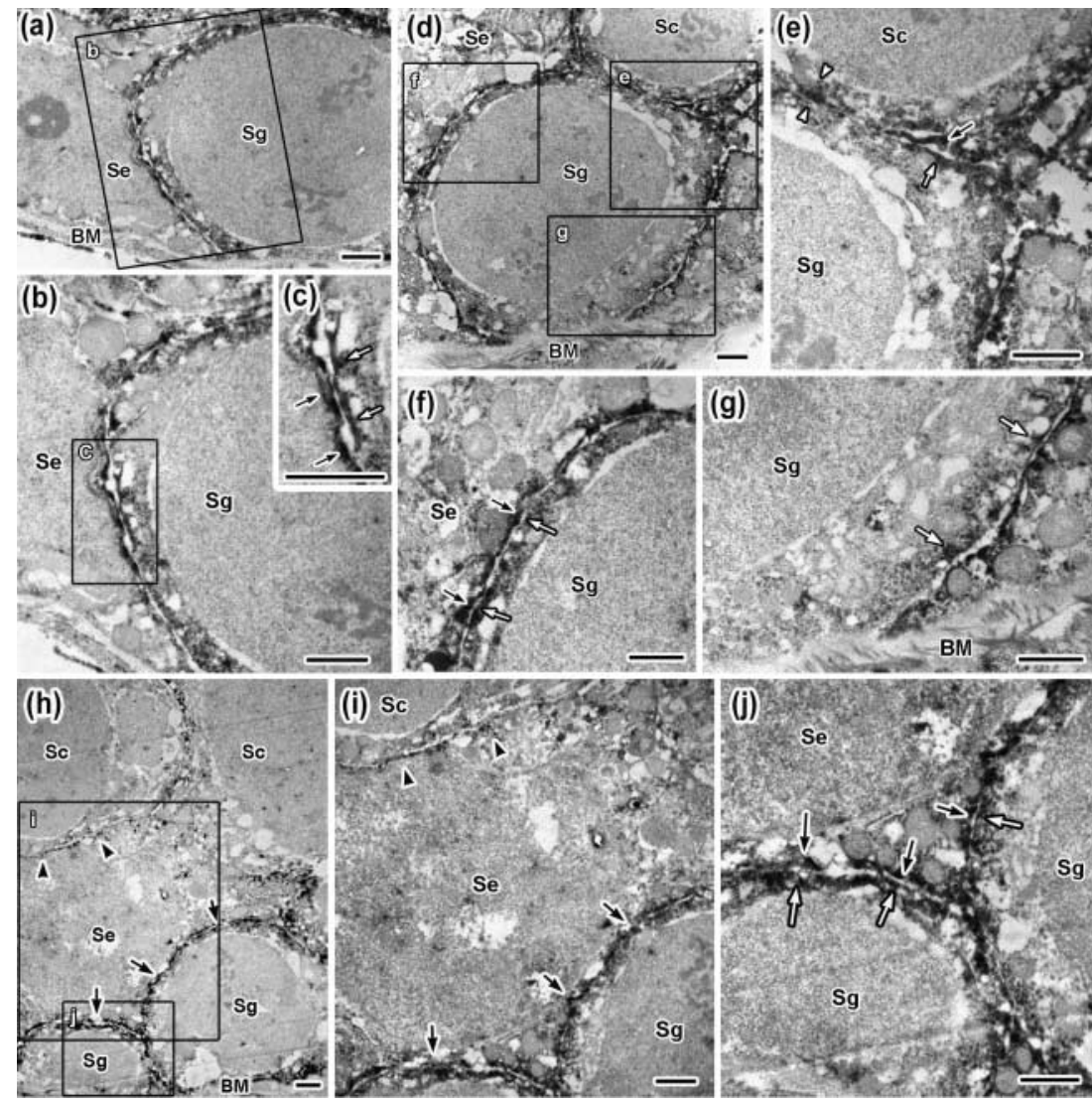

Figure 2 Immunoelectron micrographs of $4.1 \mathrm{G}$ in basal parts of mouse seminiferous tubules with the pre-embedding immunostaining method for mouse testis with perfusion fixation followed by sucrose/glycerol treatment and cryosectioning. Electron micrographs show Sertoli cells (Se) and germ cells, such as spermatogonia (Sg) and spermatocytes (Sc). Images (b), (c), (e, f, and g), and (i and j) are higher magnified views shown as black squares in (a), (b), (d), and (h) respectively. In the basal compartment, spermatogonia are attaching to Sertoli cells, and 4.1G immunodeposits are observed under cell membranes of both Sertoli cells (black arrows in c, $\mathrm{f}$, and $\mathrm{j}$ ) and spermatogonia (white arrows in c, e, f, g, and j) which are facing each other. $4.1 \mathrm{G}$ is immunolocalized along cell membranes of some spermatogonia facing spermatocytes (arrowheads in e) in addition to cytoplasmic processes of Sertoli cells (black arrow in e), whereas it is rarely immunolocalized under cell membranes attaching to basement membranes (BM in $\mathrm{d}$ and g). Intensity of the 4.1G immunodeposits between Sertoli cells and spermatogonia (arrows in $\mathrm{h}$ and i) appears to be higher than that between Sertoli cells and some spermatocytes (arrowheads in h and i). Bars (a-j) $1 \mu \mathrm{m}$. 


\section{Immunolocalization of $4.1 G$ in cultured spermatogonial stem cells}

As described in the previous paragraphs, we have realized that $4.1 \mathrm{G}$ is immunolocalized not only in Sertoli cells, but also in the spermatogonium. To confirm the $4.1 \mathrm{G}$ production and immunolocalization in germ cells, spermatogonial stem cells (SSCs) were examined in a well-established culture system by proliferating them with glial cell line-derived neurotropic factor (GDNF; Fig. 3). The SSCs were well proliferated over feeder cells (Fig. 3a-d), and clearly immunostained for 4.1G (Fig. 3a), whereas the feeder cells were rarely immunostained. The immunostaining pattern was seen to be like a honeycomb (asterisks in Fig. 3e), and such immunoreactivity was especially strong at attaching regions to the next SSCs (Fig. 3e). These findings were well recognized with confocal laser scanning microscopy (Fig. 3g-i), in which some spaces were observed between each nucleus and the $4.1 \mathrm{G}$-immunostained region like a line pattern, indicating the $4.1 \mathrm{G}$ immunolocalization at the SSC-SSC attaching sites.
Furthermore, to determine whether the expressed 4.1G protein had a similar molecular size under the cell culture condition as that in the testicular tissue, additional immunoblotting analysis was performed (Fig. 3j). The molecular weight of the 4.1G-immunopositive line obtained from lysates of the cultured SCCs was the same as the molecular weight of that obtained from the tissue lysates, indicating that the $4.1 \mathrm{G}$ protein expressed in SSCs was the same isoform.

\section{Double-immunostaining and immunoprecipitation study of $4.1 G$ and CADM1}

Next, the relationship between $4.1 \mathrm{G}$ and CADM1 was evaluated with double-immunofluorescence staining and also with an immunoprecipitation study (Fig. 4). The immunolocalization of CADM1 almost overlapped that of 4.1G in mouse testes (Fig. 4d). In addition, immunoprecipitates of CADM1 obtained from the mouse testicular tissue were immunoblotted with the anti-4.1G antibody (Fig. 4e). These findings indicate that 4.1G has a molecular complex with CADM1 in mouse seminiferous tubules.
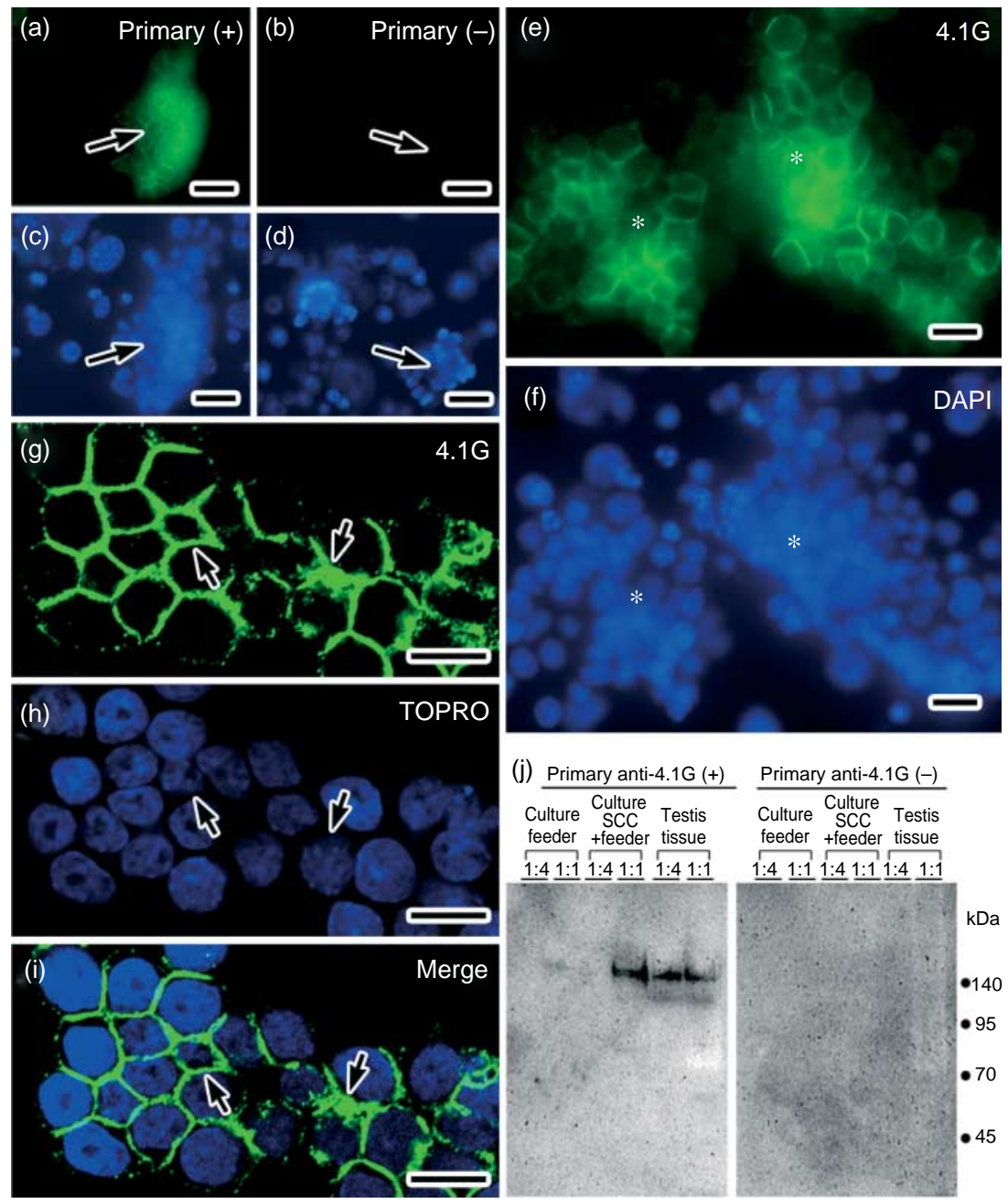

Figure 3 Immunolocalization of $4.1 \mathrm{G}$ in cultured spermatogonial stem cells (SSCs). Images (a), (b), and (e) show 4.1G immunostaining, and images (c), (d), and (f) are corresponding DAPI-nuclear staining respectively. The SSCs form cell clumps on the feeder cell layer (arrows in c and d), and 4.1G is immunolocalized in the clumps (arrow in a). Without the primary anti-4.1G antibody, the 4.1G immunostaining is eliminated (arrow in b). At higher magnified views with fluorescence microscopy (e and f), the 4.1G immunostaining shows a honeycomb pattern (asterisks in e). With confocal laser scanning microscopy, the 4.1G immunolocalization is observed as line patterns (arrows in g), and the merged image (i) of $4.1 \mathrm{G} \mathrm{(g)}$ and nuclei with TOPRO-3 (h; TOPRO) indicate the $4.1 \mathrm{G}$ immunolocalization at contact regions of SSCs. By immunoblotting analysis for 4.1G (j), the molecular size of $4.1 \mathrm{G}$ in SSCs was the same as that of the major blotted line in the mouse testicular tissue. The ratios show dilution of the cell lysates. Bars (a-d) $100 \mu \mathrm{m},(\mathrm{e}-\mathrm{i}) 20 \mu \mathrm{m}$. 

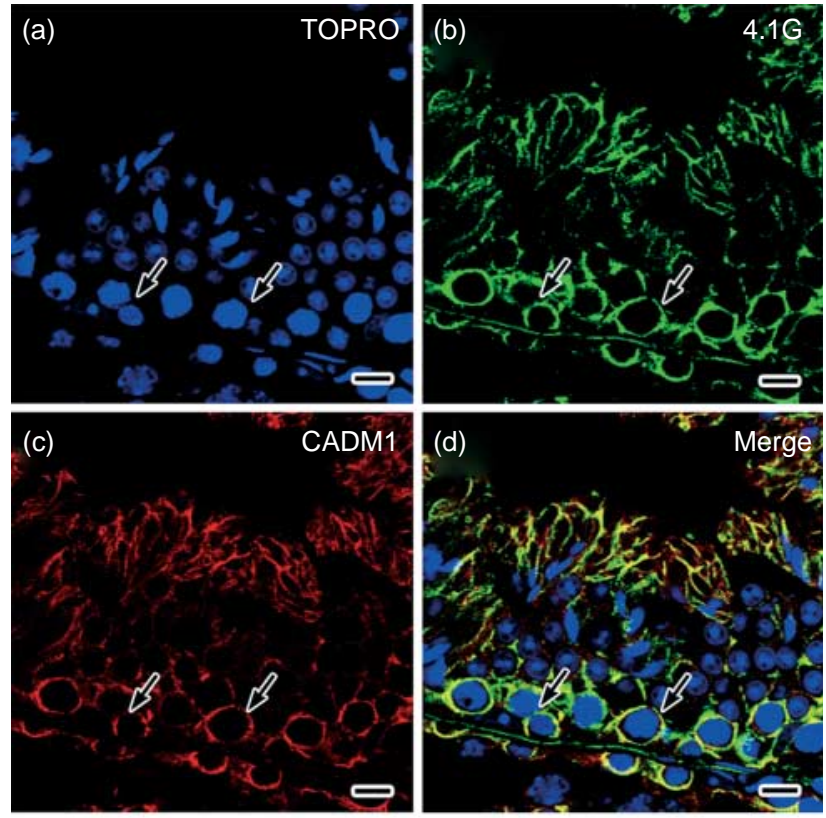

(e) IP (CADM1) - + - +

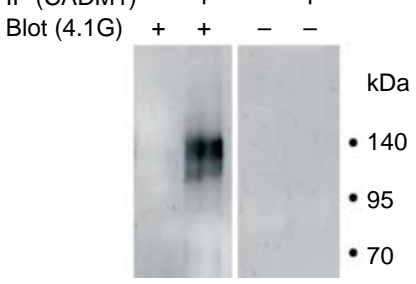

Figure 4 Double-immunostaining of 4.1G (b) and CADM1 (c) in seminiferous tubules of the mouse testes prepared with IVCT-FS, and observed with a confocal laser scanning microscope. Image (a) shows nuclear staining with TOPRO-3 (TOPRO). Both 4.1G and CADM1 proteins show linear immunostaining patterns, and the merged image (d) indicates their similar immunolocalizations. Arrows indicate the basal portions of the seminiferous tubules. From an immunoprecipitation study (e), the 4.1G immunoreaction on the blotted membrane was obtained from the CADM1 immunoprecipitated testis lysate. IP (CADM1), immunoprecipitation without $(-)$ or with $(+)$ the antiCADM1 antibody. Blot (4.1G), immunostaining of the blotted membrane with $(+)$ or without $(-)$ the anti-4.1G antibody. Bars (a-d) $20 \mu \mathrm{m}$.

\section{Morphology and immunohistochemistry in 4.1G-deficient mice}

Next, morphology of seminiferous tubules in the 4.1Gdeficient mouse testes was examined to clarify the development of germ cells without 4.1G. The 4.1Gdeficient mice were born normal and developed for at least 8 months, and male mice were fertile. Lack of the 4.1G expression was confirmed with immunohistochemistry (Fig. 5c) and western blotting analysis (Fig. 5e). Even in the 4.1G-deficient mice, the 4.1G immunoreaction in Leydig cells remained, indicating a nonspecific immunoreaction of anti-4.1G antibody. Depletion of the $4.1 \mathrm{G}$ protein in the $4.1 \mathrm{G}$-deficient mice was also confirmed in several other organs by immunohistochemistry, where we checked its expression, such as the cerebrum and sciatic nerve tissues (data not shown).

Figure $5 \mathrm{f}-\mathrm{k}$ shows representative images at each stage of the seminiferous epithelial cycle in the 4.1G-deficient mice; the timing of germ cell differentiation was not significantly disturbed as compared with that in wildtype mice shown in Fig. 1. In addition, the number of spermatozoa attaching to apical regions of Sertoli cells at stage VIII was statistically not different between the 4.1G-deficient mice and wild-type ones (Fig. 5l).

Finally, the CADM1 immunolocalization was also examined in the 4.1G-deficient mice (Fig. 6), which was almost the same as that at any stages of the seminiferous epithelial cycle in wild-type mice. Figure $6 a$ and c shows representative images of the CADM1 immunolocalization at stages I-II. These findings indicate that other unknown proteins probably rescue a $4.1 \mathrm{G}$ function to locate CADM1 at the cell membranes of germ cells.

\section{Discussion}

In this study, 4.1G was found to be immunolocalized along cell membranes of germ cells, in addition to those of Sertoli cells. In germ cells of the mouse seminiferous tubules, 4.1G was immunolocalized in spermatogonia through to early pachytene spermatocytes, as schematically summarized in Fig. 7. The 4.1G expression in the germ cells was also confirmed in cultured SSCs. Moreover, it was shown to have a molecular complex with CADM1. We also produced 4.1G-deficient mice and confirmed no expression of $4.1 \mathrm{G}$, but the morphology of their seminiferous tubules was unexpectedly well organized.

The 4.1G immunolocalization at the bottom parts of seminiferous tubules including basal compartments appeared mostly as round and/or arch-shaped patterns as shown in Fig. 1. On the other hand, we found that 4.1G was expressed in the cultured SSCs, and its immunolocalization was in the mutual attaching regions as shown in Fig. 3. These distribution patterns probably indicate a $4.1 \mathrm{G}$ function as attachment of both germ-germ and Sertoli-germ cells in the testis tissues. In the present culture system (Kubota et al. 2004), morphological interaction between SSCs and feeder cells was not so tight, resulting in SSCs tending to detach from the feeder cell layer, while such interaction among SSCs themselves was highly effective to form cell clumps. It is difficult to analyze a $4.1 \mathrm{G}$ disappearance during spermatogenesis after forming spermatocytes in vitro because of the lack of method for SSCs to differentiate into the subsequent stages such as meiosis and spermiogenesis.

Because we showed that 4.1G was immunolocalized in both germ and Sertoli cells, it may play a role in attachment of spermatogonia to each other in the basal compartment, and also in the sliding movement of spermatogonia and spermatocytes from the basal 


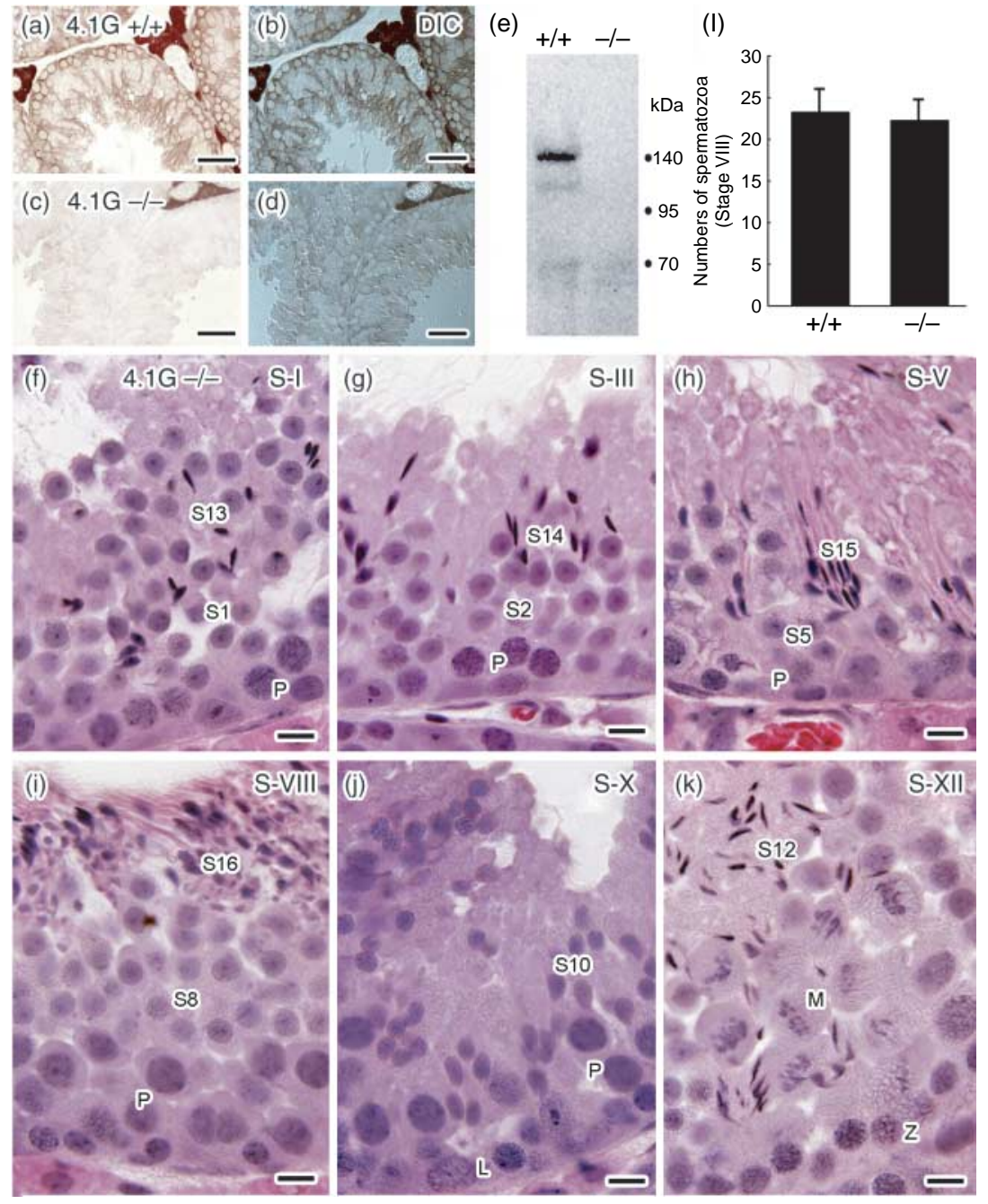

Figure 5 Morphology of seminiferous tubules in $4.1 \mathrm{G}$-deficient mouse testes obtained with IVCT-FS. The 4.1G immunostaining obtained in the wild-type mice (a) was eliminated in the $4.1 \mathrm{G}$ deficient mice (c). Images (b) and (d) show DIC images corresponding to (a) and (c) respectively. The 4.1G immunoreaction in Leydig cells remains even in the 4.1G-deficient mouse section, indicating a nonspecific DAB reaction. Western blot analysis (e) shows deletion of the $4.1 \mathrm{G}$ protein of 140 and $110 \mathrm{kDa}$ in the $4.1 \mathrm{G}$-deficient mice $(-/-)$, which are obtained in the wild-type mice $(+/+)$. HE staining images in the $4.1 \mathrm{G}$-deficient mouse seminiferous tubules show morphology at various stages (S), I (f), III (g), V (h), VIII (i), X (j), XII $(\mathrm{k})$, which are not distorted compared with those of the wild-type mice (see morphology with $\mathrm{HE}$ staining in Fig. 2). B, type B spermatogonia; Pl, preleptotene spermatocytes; $L$, leptotene spermatocytes; Z, zygotene spermatocytes; $P$, pachytene spermatocytes; $M$, meiotic division; $S 1-16$, steps of spermiogenesis. (I) The bar graph depicts similar numbers of spermatozoon attaching to apical regions of Sertoli cells at stage VIII in wild-type mice $(+/+)$ and the $4.1 \mathrm{G}$-deficinet mice $(-/-)$. Bars (a-d) $100 \mu \mathrm{m},(\mathrm{f}-\mathrm{k}) 20 \mu \mathrm{m}$. compartment into the adluminal one through the bloodtestis barrier (BTB). Some new molecules have already been identified at adhesion junctions in the seminiferous tubules (Wong et al. 2008). Recently, at the site of Sertoli cells, the 14-3-3 protein family and focal adhesion kinase (FAK) were reported to function as regulators of BTB (Siu et al. 2009, Sun et al. 2009). These two proteins are thought to detach from tight junctions with their phosphorylation, resulting in the opening of BTB. It is possible that a balance of molecular interactions among FAK, 14-3-3, and 4.1-family proteins may have functional relationship to form the BTB structure. Indeed, the FAK protein has a similar molecular structure to the FERM domain (band 4.1, ezrin, radixin, and moesin homology; Lietha et al. 2007), and the 14-3-3 protein was reported to interact with another 4.1-family protein, 4.1B (Yu et al. 2002). Because 4.1G as well as 4.1B was not immunolocalized at the lower ectoplasmic specialization where Sertoli cells formed tight junctions (Terada et al. 2004, 2005), it may be interesting to examine relative immunolocalizations of these proteins in junctional formation.

In this study, although $4.1 \mathrm{G}$ had a molecular complex with CADM1, as shown in Fig. 4, the CADM1 immunolocalization in the seminiferous tubules was not disturbed in the 4.1G-deficient mice (Fig. 6). This is probably one reason why the $4.1 \mathrm{G}$-deficient mice were able to produce sperm and sire litters in the similar way of wild-type ones, although further comprehensive analyses of spermatogenesis, spermiogenesis, and sperm functions may be needed. Thus, it became clear that $4.1 \mathrm{G}$ does not seem to be the only protein to anchor CADM1 at cell membranes of germ cells, and the membrane skeletal complex in Sertoli and germ cells seems to be much larger than we expected. Membraneassociated guanylate kinase homolog (MAGUK) proteins, such as the p55 family identified in erythrocytes and renal proximal tubules of mice (Tseng et al. 2001, Terada et al. 2007), interacting with the 4.1-family proteins, may be another carrier of CADM1 into cell 

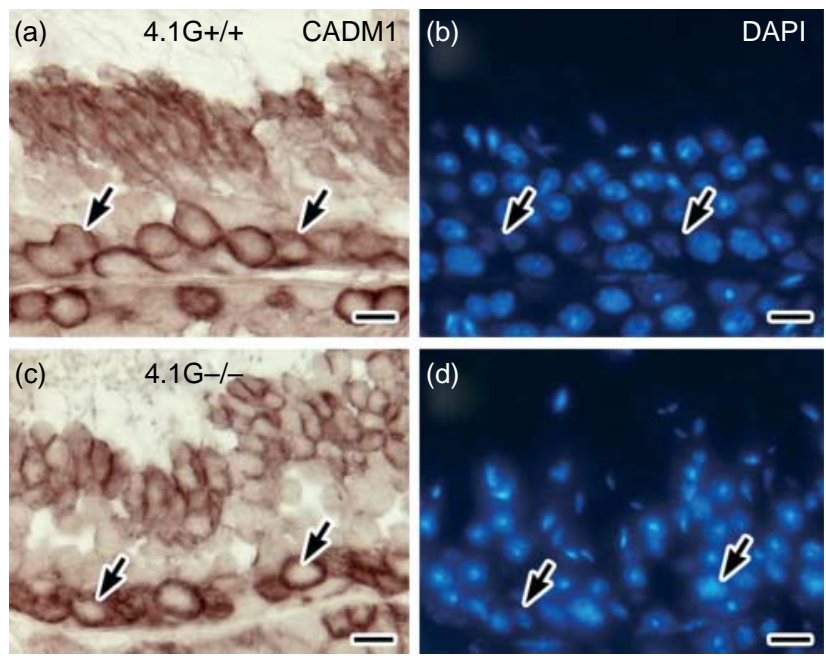

Figure 6 Immunolocalization of CADM1 in the wild-type (a) or the 4.1G-deficient (c) mouse testes obtained with IVCT-FS. Images in (b) and (d) show DAPI-staining images corresponding to the immunostaining images in (a) and (c) respectively. Note that the CADM1 immunostaining pattern is similar even in the 4.1G-deficient mice. Bars (a-d) $20 \mu \mathrm{m}$.

membranes because it has some domains attaching to the MAGUK proteins (Wakayama \& Iseki 2009). Further examination to find such a molecular complex is necessary to determine functional relevance of membrane skeletons including 4.1-family proteins in seminiferous tubules, and also analyses of CADM1deficient seminiferous tubules may help to understand the membrane skeletal complex. In addition, some 4.1-family proteins have been documented to have a tumor-suppression function (Wong et al. 2007). Another question about the $4.1 \mathrm{G}$ in the Sertoli and germ cells is whether it plays a role in tumor progression and

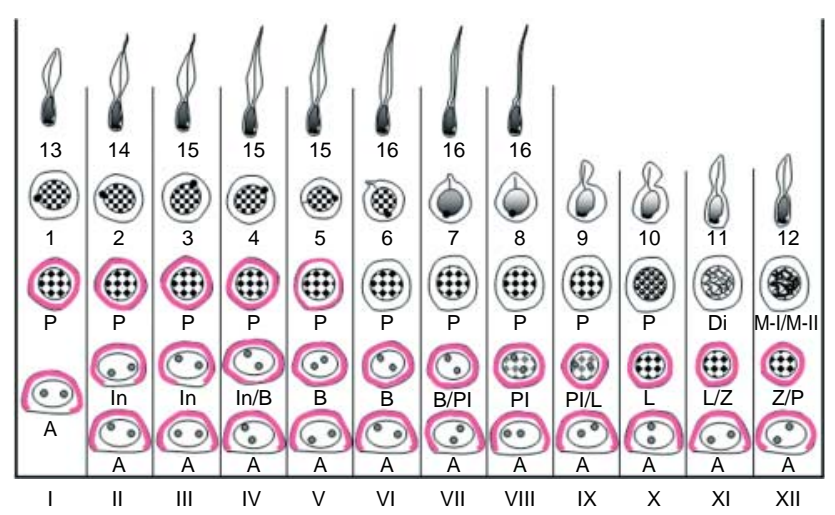

Figure 7 The $4.1 \mathrm{G}$ immunolocalization in germ cells during the mouse seminiferous epithelial cycle, which is restricted under cell membranes of spermatogonia through to early pachytene spermatocytes (pink lines). A and B, type A and B spermatogonia respectively; PI, preleptotene spermatocytes; L, leptotene spermatocytes; $Z$, zygotene spermatocytes; $P$, pachytene spermatocytes; $M$, meiotic division; 1-16, steps of spermiogenesis. appearance of phenotypes in testicular tumors without the $4.1 \mathrm{G}$ protein. In conclusion, we found the $4.1 \mathrm{G}$ localization and its molecular complex with CADM1 in germ cells.

\section{Materials and Methods}

\section{Animals and anesthesia}

All animal experiments were performed in accordance with the guidelines of the Animal Care and Use Committee in University of Yamanashi. Adult C57BL/6J mice and 4.1G-deficient mice described in the next paragraph, weighing 20-30 g, were anesthetized with pentobarbital (Terada et al. 2009b) and processed for the following preparation procedures.

\section{Production and analysis of 4.1G-deficient mice}

4.1G-deficient mice were generated by targeting exons 1 and 2 , which contain the initiation codon of 4.1G (Parra et al. 2004), using a similar procedure for the generation of 4.1Bdeficient mice (Ohno et al. 2009). A neomycin resistance cassette was inserted into the DNA fragments flanking exons 1 and 2 by using TaKaRa LA Taq (Takara Bio., Otsu, Shiga, Japan; Fig. 8a) and subcloning to a PGKneolox2DTA vector. The targeting vector was introduced into AK7 embryonic stem (ES) cells with a 129/S4 background. Neomycin-resistant cell colonies were isolated and examined by Southern blotting analysis after Xbal digestion to confirm homologous recombination. The Xbal digestion generated a $4.9 \mathrm{~kb}$ band in the wildtype allele and a $2.9 \mathrm{~kb}$ band in the mutant allele following homologous recombination (Fig. 8b). Two independent clones of ES cells, where two predicted bands sized 2.9 and $4.9 \mathrm{~kb}$ were detected in the Southern blotting, were injected into blastocytes with the C57BL/6J background and several chimeric mice were generated. Mice heterozygous for the targeted 4.1G-mutant allele were mated for at least three generations, and then those carrying two mutant alleles and a mixed background of 129/S4 and C57BL/6J were obtained. The generated mice were first genotyped by PCR screening (Fig. 8c), and lack of $4.1 \mathrm{G}$ protein was confirmed in their testicular tissues by immunohistochemistry and western blot analysis.

\section{IVCT and FS for living mouse testes}

The IVCT-FS has some benefits for preserving biological molecules, including soluble proteins of animal tissues, as well as stopping dynamic morphology reflecting their living state, as reported before (Liao et al. 2006, Ohno et al. 2007 b). Briefly, three wild-type mice or the 4.1G-deficient mice were anesthetized with pentobarbital, and IVCT was performed on their left testis by directly pouring $50 \mathrm{ml}$ liquid isopentanepropane cryogen $\left(-193^{\circ} \mathrm{C}\right)$, which was cooled in liquid nitrogen, as reported before (Liao et al. 2006, Zhou et al. 2008). The low temperature was maintained by additionally pouring liquid nitrogen $\left(-196^{\circ} \mathrm{C}\right)$. The experimental mice were always frozen under normal blood circulation conditions with their 


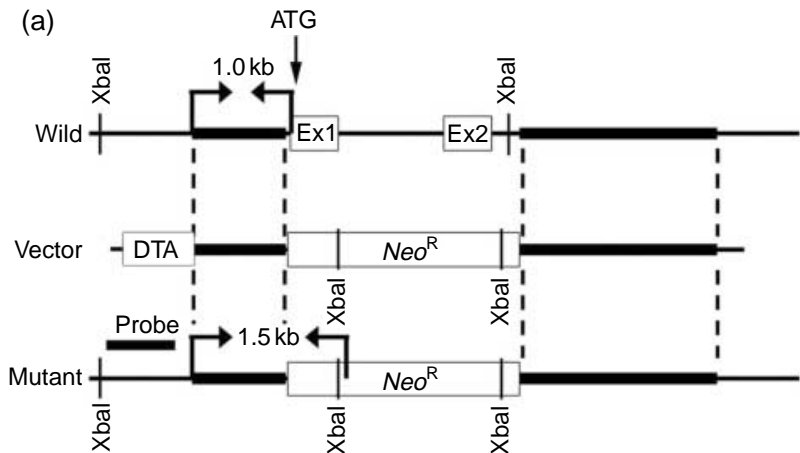

(b)
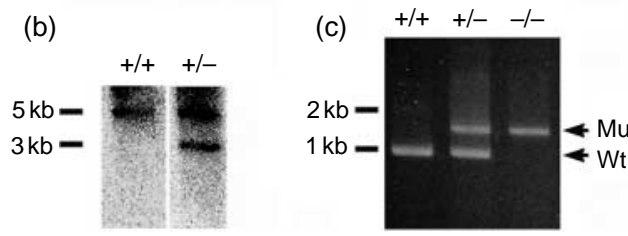

Figure 8 (a) Construction of the targeting vector (Vector) and organization of the 4.1G gene of wild-type (Wild) and mutant mice (Mutant). DTA, diphtheria toxin; Ex, exon; $\mathrm{Neo}^{R}$, neo-resistance gene; ATG, the translation initiation codon of $4.1 \mathrm{G}$; probe, a region of a digoxigenin-labeled probe for Southern blotting. DTA and Neo ${ }^{R}$ genes were inversely inserted. (b) In the Southern blotting, the genomic $D N A$ of wild-type mice $(+/+)$ digested with Xbal provides a $4.9 \mathrm{~kb}$

fragment, whereas that of heterozygous mice $(+/-)$ provides 4.9 and $2.9 \mathrm{~kb}$ fragments. (c) The PCR for the wild-type allele (Wt) produces an $\sim 1.0 \mathrm{kDa}$ DNA fragment in wild-type $(+/+)$ and heterozygous $(+/-)$ mice, whereas that for the mutant allele $(\mathrm{Mu})$ produces an $\sim 1.5 \mathrm{~kb}$

DNA fragment in heterozygous $(+/-)$ and homozygous $(-/-)$ mice.

hearts beating. The frozen testicular tissues were removed with a dental electric drill in liquid nitrogen, and processed for routine $\mathrm{FS}$ in acetone containing $2 \%$ paraformaldehyde at $-80{ }^{\circ} \mathrm{C}$ for $24 \mathrm{~h}$ and then at $-30,-10,4{ }^{\circ} \mathrm{C}$, and room temperature (RT) for $2 \mathrm{~h}$ each as reported before (Liao et al. 2006). They were washed in pure acetone and xylene, and routinely embedded in paraffin.

\section{Immunostaining on paraffin sections}

Paraffin-embedded tissues were cut at $4 \mu \mathrm{m}$ thickness, routinely de-paraffinized with xylene, and infiltrated in a graded series of ethanol and PBS. Some sections were stained with HE for pure morphology at the light microscopic level. For quantifying the number of sperm cells in both wild-type mice and 4.1Gdeficient mice, spermatozoa attaching to apical regions of Sertoli cells in $25 \mu \mathrm{m}$ width of longitudinally cut seminiferous tubules at stage VIII were counted, and the numbers were statistically compared between the 4.1G-deficient mice and the wild-type ones (five regions in three mice each).

For the common immunostaining, other adjacent sections were pretreated with hydrogen peroxide and goat normal serum, followed by rabbit polyclonal anti-protein $4.1 \mathrm{G}$ antibody which reacts with the C-terminus region of $4.1 \mathrm{G}$ (ProteinExpress, Chiba, Japan) or chicken polyclonal antiCADM1 antibody (clone 3E1; Medical and Biological Lab., Nagoya, Japan), as reported before (Ohno et al. 2007a). They were treated with biotinylated anti-rabbit IgG
(Vector, Burlingame, CA, USA) or anti-chicken IgY antibody (Jackson ImmunoReserach, Cambridgeshire, UK), and then a HRP-labeled ABC (Pierce, Rockford, IL, USA), and visualized with metal-enhanced DAB method (Pierce). Finally, they were incubated in $0.04 \%$ osmium tetroxide solution for 30-60 s and observed under a light microscope. An immunocontrol was performed without the primary anti-4.1G antibody and only with the secondary anti-rabbit IgG antibody.

For double-immunofluorescence staining for 4.1G and CADM1, some sections were incubated with both primary antibodies at the same time, and they were treated with AlexaFluor488-conjugated anti-rabbit IgG and AlexaFluor 594-conjugated anti-chicken IgY antibodies (Invitrogen). After brief staining with TOPRO-3, they were observed under a confocal laser scanning microscope (FV1000; Olympus, Tokyo, Japan).

The morphological evaluation with HE staining and the immunohistochemical study for $4.1 \mathrm{G}$ and CADM1 were performed at least in five sections from three different individuals of the wild-type mice or the 4.1G-deficient mice.

\section{Pre-embedding immunoelectron microscopy}

Conventional pre-embedding immunoelectron microscopy was performed for the mouse testes as reported before (Terada et al. 2009a). Briefly, two anesthetized mice were perfused via their hearts with $2 \%$ paraformaldehyde in $0.1 \mathrm{M} \mathrm{PB}, \mathrm{pH} 7.4$. The testicular tissues were removed, cut into small pieces with razor blades, and immersed in the same fixative at $4{ }^{\circ} \mathrm{C}$ for $2 \mathrm{~h}$. After rinsing in PBS, they were then immersed in 30\% sucrose/ $10 \%$ glycerol in $\mathrm{PB}$ at $4{ }^{\circ} \mathrm{C}$ overnight, and frozen with isopentane cooled in dry ice. Six micrometer-thick cryosections were cut and treated with $0.3 \%$ hydrogen peroxide solution and $2 \%$ goat serum in PBS, and then immunostained with the same primary anti-4.1G antibody. They were subsequently incubated with biotinylated goat anti-rabbit IgG antibody. After rinsing in PBS, they were fixed again with $0.25 \%$ glutaraldehyde in PB for 10 min and visualized by the ABC-DAB method, as reported before (Terada et al. 2009a). Then, they were additionally treated with $1 \% \mathrm{OsO}_{4}$ in $\mathrm{PB}$ for $20 \mathrm{~min}$. The immunostained tissues were dehydrated with a graded series of ethanol and routinely embedded in epoxy resin by the inverted gelatin capsule method (Terada et al. 2005). Ultrathin sections of $70 \mathrm{~nm}$-thickness were routinely cut on an ultramicrotome and collected on copper grids. They were stained only with uranyl acetate, and observed in an electron microscope (H-7500; Hitachi) at an accelerating voltage of $75 \mathrm{kV}$.

\section{Immunoprecipitation analysis}

The immunoprecipitation analysis was performed for the adult C57BL/6J mouse testes, as reported before (Terada et al. 2007). For the 4.1G-CADM1 interaction, tissue lysates were obtained from the tissue supernatant by homogenization with TENT buffer $(20 \mathrm{mM}$ Tris pH 7.4, $1 \mathrm{mM}$ EDTA, $50 \mathrm{mM} \mathrm{NaCl}, 1 \%$ Triton $\mathrm{X}$-100) containing a protease inhibitor cocktail (Sigma) and centrifugation at $10000 \mathrm{~g}$ at $4{ }^{\circ} \mathrm{C}$ for $30 \mathrm{~min}$. The lysates were treated with protein G-Sepharose (GE Healthcare, 
Piscataway, NJ, USA) and incubated with chicken anti-CADM1 antibody at $4{ }^{\circ} \mathrm{C}$ overnight. On the following day, goat antichicken IgY antibody was also added at $4{ }^{\circ} \mathrm{C}$ for $8 \mathrm{~h}$, and then immunocomplexes were separated using protein G-Sepharose. All proteins were eluted from the sepharose beads by boiling in Laemmli sample buffer and subjected to SDS-PAGE and western blotting analyses with the anti-4.1G antibody. The blots were visualized using a chemiluminescent system (Pierce).

\section{Cell culture}

SSC cultures were established from $\mathrm{C} 57 \mathrm{BL} / 6 \mathrm{~N}$ pup testes as described previously (Kubota \& Brinster 2008). The SSCs provide a model to study stem cell biology because they undergo self-renewal and transmit genes to subsequent generations (Kubota et al. 2004). Germ cell clumps containing SSCs were maintained on mitotically inactivated STO cell feeders (SNL76/7; a kind gift from Dr Allan Bradley, Wellcome Trust Sanger Institute, Cambridge, UK) using a serum-free medium supplemented with $10 \mathrm{ng} / \mathrm{ml}$ human GDNF (R\&D Systems, Minneapolis, MN, USA) and $1 \mathrm{ng} / \mathrm{ml}$ basic fibroblast growth factor (BD Biosciences, San Jose, CA, USA).

For the western blot analysis, SSCs, feeder cells, or testicular tissues were directly lysed with Laemmli sample buffer including $\beta$-mercaptoethanol at $95{ }^{\circ} \mathrm{C}$, electrophoresed in $5-20 \%$ SDS-PAGE, blotted on PVDF membranes, and immunostained with the anti-4.1G antibody. For the fluorescence immunostaining, the cultured cells in dishes were fixed with $2 \%$ paraformaldehyde in $0.1 \mathrm{M}$ PB for $15 \mathrm{~min}$, and treated with $0.5 \%$ saponin in PBS at RT for $1 \mathrm{~h}$. They were incubated with anti-4.1G antibody at RT for $2 \mathrm{~h}$ and then with AlexaFluor488-conjugated anti-rabbit IgG antibody (Invitrogen) at RT for $1 \mathrm{~h}$. After brief counter-staining with DAPI (Vector) or TOPRO-3, they were observed under a fluorescence microscope or a confocal laser scanning microscope (FV1000; Olympus).

\section{Declaration of interest}

The authors declare that there is no conflict of interest that could be perceived as prejudicing the impartiality of the research reported.

\section{Funding}

This work was partially supported by a grant from the Japan Society for the Promotion of Science (KAKENHI \#21590214) to $\mathrm{N}$ Terada.

\section{Acknowledgements}

The authors thank Mr Yutaka Kitahara in Department of Anatomy and Molecular Histology, University of Yamanashi, Interdisciplinary Graduate School of Medicine and Engineering, for his technical assistance.

\section{References}

Discher DE, Winardi R, Schischmanoff PO, Parra M, Conboy JG \& Mohandas N 1995 Mechanochemistry of protein 4.1 spectrin-actinbinding domain: ternary complex interactions, membrane binding, network integration, structural strengthening. Journal of Cell Biology 130 897-907.

Fujita E, Tanabe Y, Hirose T, Aurrand-Lions M, Kasahara T, Imhof BA, Ohno S \& Momoi T 2007 Loss of partitioning-defective-3/isotypespecific interacting protein (Par-3/ASIP) in elongating spermatid of RA175 (IGSF4A/SynCAM)-deficient mice. American Journal of Pathology 171 1800-1810.

Kubota H \& Brinster RL 2008 Culture of rodent spermatogonial stem cells, male germline stem cells of the postnatal animal. Methods in Cell Biology 86 59-84.

Kubota H, Avarbock MR \& Brinster RL 2004 Growth factors essential for self-renewal and expansion of mouse spermatogonial stem cells. PNAS 101 16489-16494.

Liao X, Terada N, Ohno N, Li Z, Fujii Y, Baba T \& Ohno S 2006 Immunohistochemical study of serum albumin in normal and cadmiumtreated mouse testis organs by "in vivo cryotechnique". Histology and Histopathology 21 35-40.

Lietha D, Cai X, Ceccarelli DF, Li Y, Schaller MD \& Eck MJ 2007 Structural basis for the autoinhibition of focal adhesion kinase. Cell $\mathbf{1 2 9}$ 1177-1187.

Lu D, Yan H, Othman T, Turner CP, Woolf T \& Rivkees SA 2004a Cytoskeletal protein $4.1 \mathrm{G}$ binds to the third intracellular loop of the A1 adenosine receptor and inhibits receptor action. Biochemical Journal 377 51-59.

Lu D, Yan H, Othman T \& Rivkees SA 2004b Cytoskeletal protein 4.1G is a binding partner of the metabotropic glutamate receptor subtype 1 alpha. Journal of Neuroscience Research 78 49-55.

Ohno S, Terada N, Fujii Y, Ueda H \& Takayama I 1996 Dynamic structure of glomerular capillary loop as revealed by in vivo cryotechnique. Virchows Archiv 427 519-527.

Ohno N, Terada N, Tanaka J, Yokoyama A, Yamakawa H, Fujii Y, Baba T, Ohara O \& Ohno S 2005 Protein 4.1G localizes in rodent microglia. Histochemistry and Cell Biology 124 477-486.

Ohno N, Terada N, Yamakawa H, Komada M, Ohara O, Trapp BD \& Ohno S 2007a Expression of protein 4.1G in Schwann cells of the peripheral nervous system. Journal of Neuroscience Research $\mathbf{8 4}$ 568-577.

Ohno N, Terada N, Saitoh S \& Ohno S 2007 bxtracellular space in mouse cerebellar cortex revealed by in vivo cryotechnique. Journal of Comparative Neurology 505 292-301.

Ohno N, Terada N, Komada M, Saitoh S, Costantini F, Pace V, Germann PG, Weber K, Yamakawa H, Ohara O et al. 2009 Dispensable role of protein 4.1B/DAL-1 in rodent adrenal medulla regarding generation of phechromocytoma and plasmalemmal localization of TSLC1. Biochimica et Biophysica Acta 1793 506-515.

Parra M, Gascard P, Walensky LD, Snyder SH, Mohandas N \& Conboy JG 1998 Cloning and characterization of 4.1G (EPB41L2), a new member of the skeletal protein 4.1 (EPB41) gene family. Genomics 49 298-306.

Parra M, Gee S, Chan N, Ryaboy D, Dubchak I, Mohandas N, Gascard PD \& Conboy JG 2004 Differential domain evolution and complex RNA processing in a family of paralogous EPB41 (protein 4.1) genes facilitate expression of diverse tissue-specific isoforms. Genomics $\mathbf{8 4}$ 637-646.

Ralston KJ, Hird SL, Zhang X, Scott JL, Jin B, Thorne RF, Berndt MC, Boyd AW \& Burns GF 2004 The LFA-1-associated molecule PTA-1 (CD226) on T cells forms a dynamic molecular complex with protein 4.1G and human discs large. Journal of Biological Chemistry 279 33816-33828.

Saito M, Sugai M, Katsushima Y, Yanagisawa T, Sukegawa J \& Nakahata N 2005 Increase in cell-surface localization of parathyroid hormone receptor by cytoskeletal protein 4.1G. Biochemical Journal 392 75-81.

Sakisaka T, Ikeda W, Ogita H, Fujita N \& Takai Y 2007 The roles of nectins in cell adhesions: cooperation with other cell adhesion molecules and growth factor receptors. Current Opinion in Cell Biology 19 593-602.

Siu ER, Wong EW, Mruk DD, Porto CS \& Cheng CY 2009 Focal adhesion kinase is a blood-testis barrier regulator. PNAS 106 9298-9303. 
Sun I, Wong E, Li M, Lee W \& Cheng CY 2009 14-3-3 and its binding partners are regulators of protein-protein interactions during spermatogenesis. Journal of Endocrinology 47 13-23.

Surace EI, Strickland A, Hess RA, Gutmann DH \& Naughton CK 2006 Tslc1 (nectin-like molecule-2) is essential for spermatozoa motility and male fertility. Journal of Andrology 27 816-825.

Tateyama M \& Kubo Y 2007 Coupling profile of the metabotropic glutamate receptor 1 alpha is regulated by the C-terminal domain. Molecular and Cellular Neurosciences 34 445-452.

Terada N, Ohno N, Yamakawa H, Baba T, Fujii Y, Zea Z, Ohara O \& Ohno S 2004 Immunohistochemical study of protein 4.1B in the normal and W/W ${ }^{v}$ mouse seminiferous epithelium. Journal of Histochemistry and Cytochemistry 52 769-777.

Terada N, Ohno N, Yamakawa H, Ohara O, Liao X, Baba T \& Ohno S 2005 Immunohistochemical study of a membrane skeletal molecule, protein 4.1G, in mouse seminiferous tubules. Histochemistry and Cell Biology 124 303-311.

Terada N, Ohno N, Saitoh S, Seki G, Komada M, Suzuki T, Yamakawa H, Soleimani M \& Ohno S 2007 Interaction of membrane skeletal protein, protein 4.1B and p55, and sodium bicarbonate cotransporter1 in mouse renal S1-S2 proximal tubules. Journal of Histochemistry and Cytochemistry 55 1199-1206.

Terada N, Ohno N, Saitoh S, Saitoh Y, Fujii Y, Kondo T, Katoh R, Chan C, Abraham SN \& Ohno S 2009a Involvement of dynamin-2 in formation of discoid vesicles in urinary bladder umbrella cells. Cell and Tissue Research 337 91-102.

Terada N, Ohno N, Saitoh S, Saitoh Y \& Ohno S $2009 \mathrm{~b}$ Immunoreactivity of glutamate in mouse retina inner segment of photoreceptors with in vivo cryotechnique. Journal of Histochemistry and Cytochemistry 57 883-888.

Tseng TC, Marfatia SM, Bryant PJ, Pack S, Zhuang Z, O'Brien JE, Lin L, Hanada T \& Chishti AH 2001 VAM-1: a new member of the MAGUK family binds to human Veli-1 through a conserved domain. Biochimica et Biophysica Acta 1518 249-259.

Wakayama T \& Iseki S 2009 Role of the spermatogenic-Sertoli cell interaction through cell adhesion molecule-1 (CADM1) in spermatogenesis. Anatomical Science International 84 112-121.

Wakayama T \& Koami H 2003 Expression and functional characterization of the adhesion molecule spermatogenic immunoglobulin superfamily in the mouse testis. Biology of Reproduction 68 1755-1763.
Wakayama T, Ohashi K, Mizuno K \& Iseki T 2001 Cloning and characterization of a novel mouse immunoglobulin superfamily characterization in early spermatogenic cells. Molecular Reproduction and Development 60 158-164.

Walensky LD, Dawson TM, Steiner JP, Sabatini DM, Suarez JD, Klinefelter GR \& Snyder SH 1998 The 13-kD FK506 binding protein, FKBP13, interacts with a novel homologue of the erythrocyte membrane cytoskeletal protein 4.1. Journal of Cell Biology 141 143-158.

van der Weyden L, Arends MJ, Chausiaux OE, Ellis PJ, Lange UC, Surani MA, Affara N, Murakami Y, Adams DJ \& Bradley A 2006 Loss of TSLC1 causes male infertility due to a defect at the spermatid stage of spermatogenesis. Molecular and Cellular Biology 26 3595-3609.

Wong SY, Haack H, Kissil JL, Barry M, Bronson RT, Shen SS, Whittaker CA, Crowley D \& Hynes RO 2007 Protein 4.1B suppresses prostate cancer progression and metastasis. PNAS 104 12784-12789.

Wong EW, Mruk DD \& Cheng CY 2008 Biology and regulation of ectoplasmic specialization, an atypical adhesion junction type, in the testis. Biochimica et Biophysica Acta 1778 692-708.

Yamada D, Yoshida M, Williams YN, Fukami T, Kikuchi S, Masuda M, Maruyama T, Ohta T, Nakae D, Maekawa A et al. 2006 Disruption of spermatogenic cell adhesion and male infertility in mice lacking TSLC1/IGSF4, an immunoglobulin superfamily cell adhesion molecule. Molecular and Cellular Biology 26 3610-3624.

Yu T, Robb VA, Singh V, Gutmann DH \& Newsham IF 2002 The 4.1/ezrin/radixin/moesin domain of the DAL-1/protein 4.1B tumor suppression interacts with 14-3-3 proteins. Biochemical Journal 365 783-789.

Zhou H, Ohno N, Terada N, Saitoh S, Naito I \& Ohno S 2008 Permselectivity of blood follicle barriers in mouse ovaries of the mifepristone-induced polycystic ovary model revealed by in vivo cryotechnique. Reproduction 136 599-610.

Received 6 January 2010

First decision 2 February 2010

Revised manuscript received 9 February 2010

Accepted 3 March 2010 